\title{
The Immunosuppressant FK506 Increases the Rate of Axonal Regeneration in Rat Sciatic Nerve
}

\author{
Bruce G. Gold, ${ }^{1,2}$ Kiyoshi Katoh, ${ }^{1, a}$ and Toni Storm-Dickerson' \\ ${ }^{1}$ Center for Research on Occupational and Environmental Toxicology and ${ }^{2}$ Department of Cell Biology and \\ Anatomy, Oregon Health Sciences University, Portland Oregon 97201-3098
}

The axonal regenerative properties of the new immunosuppressant drug FK506 (tacrolimus) are further explored in this continuing study. In an initial report (Gold et al., 1994a), we described the ability of FK506 to reduce the time until return of function in the hind feet of rats following a sciatic nerve crush. In the present study, we examined the morphological correlate underlying this enhancement of functional recovery. In rats receiving daily subcutaneous injections of FK506 (1.0 mg/kg) for $18 \mathrm{~d}$ following a sciatic nerve crush the regenerating axons appeared larger in size compared to saline-injected control animals. Morphometric analysis of axonal calibers in the soleus nerve demonstrated that mean axonal areas for the largest $30 \%$ of axons were increased over axotomized control values by $93 \%$ in the FK506-treated animals. Next, the rate of axonal regeneration was determined by radiolabeling the L5 dorsal root ganglion (DRG) at 9 and $14 \mathrm{~d}$ following axotomy. Regression analysis of the outgrowth distances for sensory axons between 10 and $15 \mathrm{~d}$ revealed a $16 \%$ increase in regeneration rate. Electron microscopy of intramuscular nerve branches in the interosseus muscles confirmed that the axons in the FK506-treated animals were further advanced toward their targets; in some instances, axons were shown to reinnervate muscle spindles. The results are discussed in terms of the known ability of FK506 to inhibit the activity protein phosphatase 2B (calcineurin).

[Key words: calcineurin, dorsal root ganglion, immunosuppressants, neuroregeneration, peripheral nerve, phosphatase inhibitors, T-cells]

FK506 (tacrolimus), isolated from Streptomeyces tsukubaensis (Kino et al., 1987a,b), is a new FDA-approved immunosuppressant. The drug may replace cyclosporin $A$ as the drug of choice for organ transplants due to its greater potency and relatively diminished side-effects, notably, nephrotoxicity (Starzl et al., 1987, 1989; Hoffman et al., 1990; see, however, Klintmalm,

\footnotetext{
Received Feb. 23, 1995; revised July 14, 1995; accepted July 19, 1995.

We thank Dr. Michael S. Gold (University of New Mexico) for his generous gift of FK506. We also thank Dr. Peter Spencer for critical review of the manuscript and Mr. Dan Austin for preparation of the micrographs. This study was supported by funds from the US Public Health Service Grant NIH NS19611 and from the Paralyzed Veterans of America Spinal Cord Research Foundation.

Correspondence should be addressed to Bruce G. Gold, Ph.D., Center for Research on Occupational and Environmental Toxicology/L606. Oregon Health Sciences University, 3181 S.W. Sam Jackson Park Road, Portland, OR 972013098 .

"Present address: Department of Public Health, Akita University School of Medicine, Hondo, Akita, Japan.

Copyright (c) 1995 Society for Neuroscience $\quad 0270-6474 / 95 / 157509-08 \$ 05.00 / 0$
}

1994). While neurological complications are prevalent in patients given FK506 following liver transplantation (Eidelman et al., 1991; Alessiani et al., 1993), these have been attributed to systemic illness rather to drug toxicity (Burkhalter et al., 1994).

In addition to its ability to suppress T-cell activity. FK506 has a number of nonimmune effects, including inhibition of the growth of the bacterium Saccharomyces cerevisiae (Heitman et al., 1993; Schmidt et al., 1994), stimulation of hair growth in mammals (Yamamoto et al., 1994), and in humans, liver cell regeneration (Carroll et al., 1994) and wound healing (Francavilla et al., 1989). Two recent studies (Gold et al., 1994a; Lyons et al., 1994) indicate that FK506 also influences process outgrowth in neurons. First, Snyder and coworkers (Lyons et al., 1994) reported that FK506 increases nerve growth factor (NGF)induced neurite outgrowth in PC12 cells and primary cultures of DRG sensory neurons. Second, we have presented an initial report (Gold et al., 1994a) showing that FK506 enhances recovery of function following a sciatic nerve crush (axotomy) lesion in the rat.

In the present report, we have extended our initial observations (Gold et al., 1994a) on the regenerative properties of FK506. The data reveal that the previously observed beneficial effects of FK506 on functional recovery is due to an enhancement in the rate of axonal elongation resulting in a more rapid maturation of axonal sprouts. Portions of this work have appeared previously in abstract form (Gold et al., 1994b; Katoh and Gold, 1995).

\section{Materials and Methods}

Preparation of FK506. FK506 was isolated from capsules (Fujisawa Pharmaceutical, Osaka, Japan), $10 \mathrm{mg}$ suspended in saline $(5 \mathrm{ml})$, the suspension centrifuged at $25,000 \times g$ for $10 \mathrm{~min}$ at $4^{\circ} \mathrm{C}(2 \times)$ and the nonsoluble filler contained in the capsules discarded. The solution was found by HPLC to contain approximately $10 \%$ of the original $10 \mathrm{mg}$ content of FK506 (Gold et al., 1994a); no spurious peaks were identified by HPLC analysis, indicating that the resultant solution contained only trace levels of the filler materials.

Animals and surgical procedures. A total of 24 male Sprague-Dawley rats was used in this study; the 10 rats used for morphological analysis were from a previous study (Gold et al., 1994a). Rats were deeply anesthetized with $2 \%$ halothane prior to surgery. The sciatic nerve was exposed unilaterally and crushed twice (for a total of $30 \mathrm{sec}$ using a no. 7 Dumont jeweler's forceps), either at the level of the hip (for morphological studies) or at the junction of the L4 and L5 spinal nerves (for measurement of axonal regeneration rate). A suture was tied in the adjacent muscle to mark the crush site. Beginning on the day of nerve crush, operated animals received daily subcutaneous injections (in the back of the neck) of either FK506 $(1.0 \mathrm{mg} / \mathrm{kg})$ or an equivalent volume of saline $(5 \mathrm{ml} / \mathrm{kg})$ for $18 \mathrm{~d}$

Tissue fixation and preparation. At $18 \mathrm{~d}$ following axotomy, 10 animals (five per group) were anesthetized with $4 \%$ halothane, heparinized, and perfused through the ascending aorta with $4 \%$ paraformalde- 

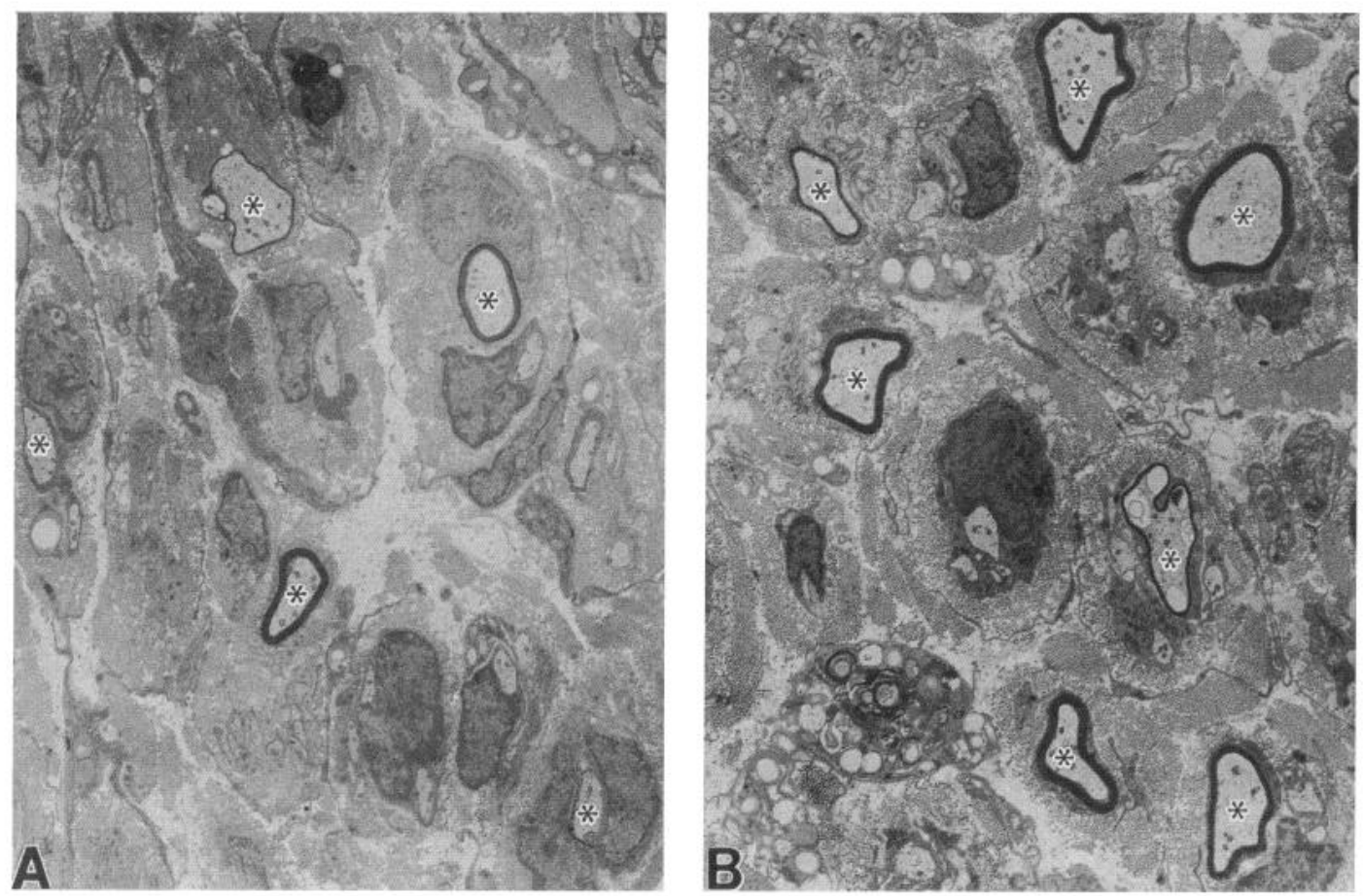

Figure 1. Nerves distal to the crush site demonstrate a more advanced stage of regeneration in FK506-treated rats $18 \mathrm{~d}$ following axotomy. Representative electron micrographs from saline-treated $(A)$ and FK506-treated $(B)$ animals in the medial gastrocnemius nerve. Axons (asterisks) are larger in size and are surrounded by thicker (albeit relatively thin for axonal calibers) myelin sheaths in the nerve from the FK506-treated animal. Magnification, $3000 \times$

hyde in $0.1 \mathrm{M}$ sodium phosphate buffer $(\mathrm{pH} 7.4)$ for $10 \mathrm{sec}$ followed by 1 liter of $5 \%$ glutaraldehyde in $0.1 \mathrm{~m}$ sodium phosphate buffer $(\mathrm{pH}$ 7.4). The following tissues were sampled: sciatic nerve, peroneal nerve, sural nerve, tibial nerve, tibial branches supplying the medial gastrocnemius and soleus muscles, and interosseus muscles. Tissues were placed in $0.1 \mathrm{~m}$ sodium phosphate buffer ( $\mathrm{pH} 7.4$ ), postfixed with $2 \%$ osmium tetroxide (in $0.1 \mathrm{M}$ phosphate buffer) for $2.5 \mathrm{hr}$, dehydrated in ascending concentrations of ethanol, and embedded in plastic (Spurr's). Thick sections $(1 \mu \mathrm{m})$ were stained with toluidine blue; thin sections were stained with uranyl acetate followed by lead citrate, and examined in a JOEL electron microscope.

Morphometric analysis. Analysis of axonal calibers was performed in the branch of the posterior tibial nerve supplying the soleus muscle. For each animal, the entire nerve cross-section (excluding a rare area obscured by a grid bar) was photographed at a magnification of $4000 \times$ (totaling 10-12 fields per nerve). Photographic prints (final magnification $10,000 \times$ ) were made of between 106-211 axons in each nerve. Axonal areas of both myelinated and unmyelinated fibers were determined by tracing the axolemma using a Houston Instrument HI-PAD digitizing tablet connected to an IBM XT computer with appropriate software (BIOOUANT IV, R\&M Biometrics, Nashville, TN). Cumulative histograms were constructed from these data. Since axonal areas did not demonstrate a normal distribution, we selected the largest $30 \%$ of axons from each nerve for purposes of statistical analysis. Individual mean axonal area from this population of axons was determined for each nerve. For each group (i.e., FK506 and saline), mean values and standard errors were calculated based upon these individual means. Mean values for axonal areas were compared using a two-tailed Student's $t$ test (STATVIEw, Abacus Concepts, Inc., Berkeley, CA).

Measurement of axonal regeneration rate. For measurement of axonal outgrowth distances, FK506-treated and saline-treated axotomized rats were deeply anesthetized with chloral hydrate $(400 \mathrm{mg} / \mathrm{kg}$, i.p. $)$, a laminectomy performed, and the L5 DRG unilaterally injected with 20 $\mu \mathrm{Ci}$ of ${ }^{3} \mathrm{H}$-leucine (Amersham, specific activity $150 \mathrm{Ci} / \mathrm{mmol}$ ) on day 9 (four animals per group) or day 14 (three animals per group). Body temperature was thermostatically maintained at $37^{\circ} \mathrm{C}$ (Harvard Instruments) during the period of anesthesia. Twenty-four hours later (days 10 and 15 , respectively), the animals were killed by euthanasia solution and the nerves (L5 spinal roots to the distal sciatic nerve branches) harvested intact to determine the maximal extent of transported proteinincorporated radioactivity (Droz and Warshawsky, 1963). Briefly, the nerves were placed in $10 \%$ formalin overnight (to remove non-proteinbound radioactivity), cut into $3 \mathrm{~mm}$ segments, and each segment solubilized in $0.5 \mathrm{ml}$ of Solvable (NEN Research Products, Boston MA) at $60^{\circ} \mathrm{C}$ for $4 \mathrm{hr}$ and the radioactivity determined in a liquid scintillation spectrometer (Beckman); data were expressed as disintegrations per minute $(\mathrm{dpm})$. For each nerve, $\mathrm{dpm}$ were plotted against the distance from the crush site and the maximal extent of outgrowth was determined from the point of intercept between a line drawn through the front of radioactivity collected in the distal portion of the nerve over the $24 \mathrm{hr}$ period and the background radioactivity (Ochs and Ranish, 1970). Mean values for outgrowth distances were calculated, the values plotted against the number of days since axotomy, a regression line generated (STATVIEw, Abacus Concepts, Inc., Berkeley, CA), and the slope of the line used to estimate the rate of axonal regeneration between the two time points of study (i.e., 10 and $15 \mathrm{~d}$ ); sufficient drug was not available for examination of a third time point.

\section{Results}

\section{FK506 accelerates the maturation and extent of elongation of regeneration axons}

As previously reported (Gold et al., 1994a), a higher density of regenerating myelinated axons was observed at all levels distal to the crush site [e.g., soleus (see Fig. 5 in Gold et al., 1994a) and medial gastrocnemius (Fig. 1) nerves] in FK506-treated compared with saline-treated animals at $18 \mathrm{~d}$ following axotomy. High-power electron microscopy revealed many premyelinating (Fig. 2A) and early myelinating (Fig. 2B) axons from salinetreated animals. In contrast, axons from animals given FK506 were commonly larger in size and in a more advanced stage of myelination (Fig. 2C,D).

Morphometric analysis of axonal calibers in the soleus nerve (see Materials and Methods) demonstrated a shift to larger sized axons in the FK506-treated animals (Fig. 3). Mean axonal areas 

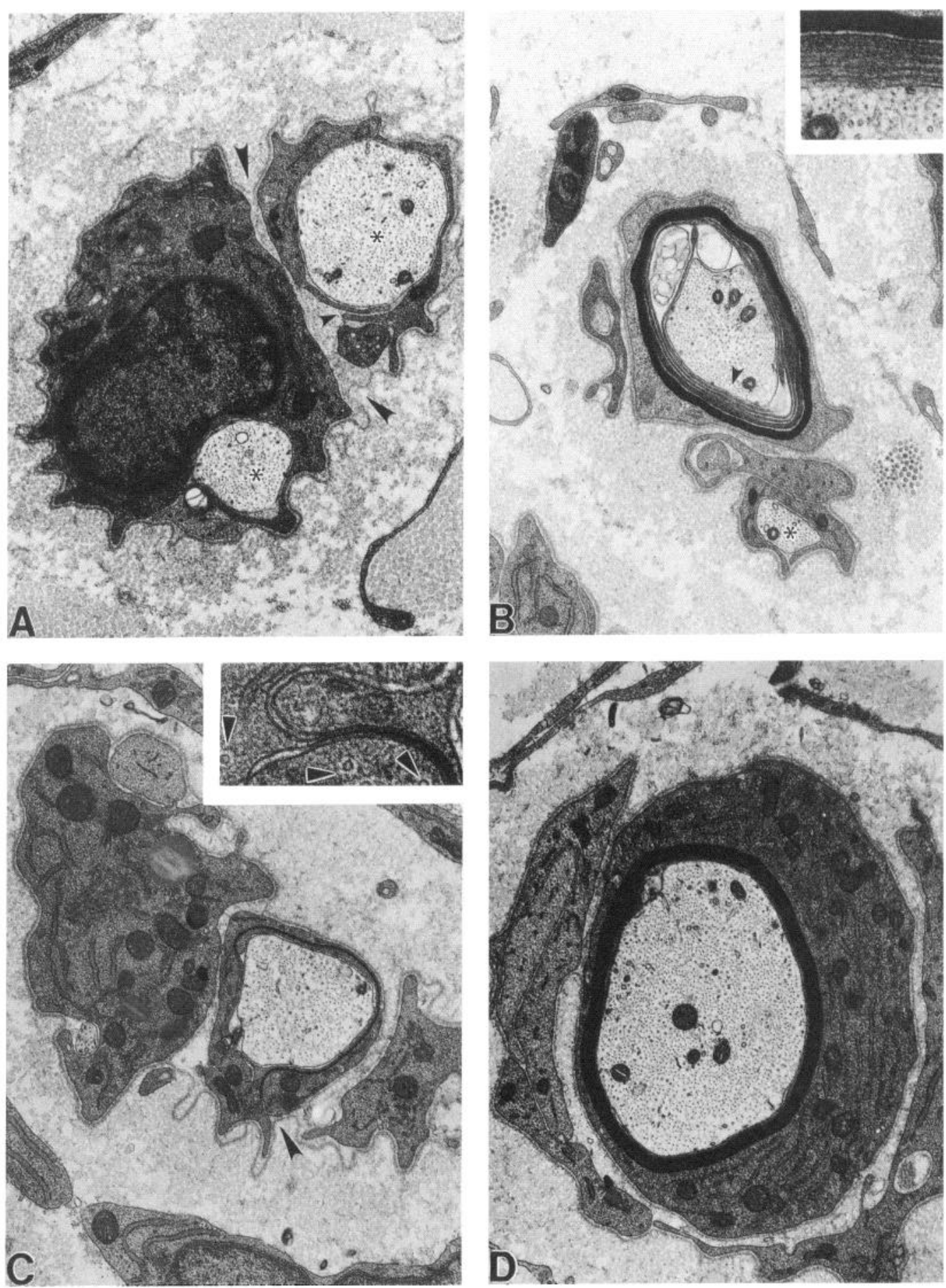

Figure 2. Regenerating axons are in a more advanced stage of myelination in FK506-treated rats at $18 \mathrm{~d}$ following axotomy. Electron micrographs of representative axons in the soleus nerve from saline-treated $(A, B)$ and FK506-treated $(C, D)$ animals. A, Two premyelinated axons (asterisks) surrounded by Schwann cells are still contained within a common basal lamina (large arrowheads). Note that the lips of a Schwann cell process have begun to envelope one axon (small arrowhead) prior to forming a mesaxon. B, A myelinating axon. Note inner-most lamellae remain uncompacted; one region (small arrowhead) is shown at higher power in inset. A small, nonmyelinated axon (asterisk) is also present. $C$, An axon undergoing early myelination. Membrane fusion begins at hair-pin loop (large arrowhead), as shown at higher power in inset. Note microtubules (arrowheads) in Schwann cell cytoplasm. D, A large axon exhibiting a normal appearing, thick myelin sheath. 14,000 $\times ; 40,000 \times($ inset in B); $66,000 \times$ (inset in $C$ ).

for the total population of fibers in the soleus nerve $18 \mathrm{~d}$ following axotomy were significantly $(p<0.005)$ increased from $0.6 \pm 0.08 \mu \mathrm{m}^{2}$ in the saline-treated animals to $1.0 \pm 0.08 \mu \mathrm{m}^{2}$ in the FK506-treated animals. The presence of many very small axons (most likely representing axons not destined for myelination) tended to skew the distributions towards the smaller sizes. Since these small axons were more numerous in nerves from saline-treated animals, a somewhat larger total number of 


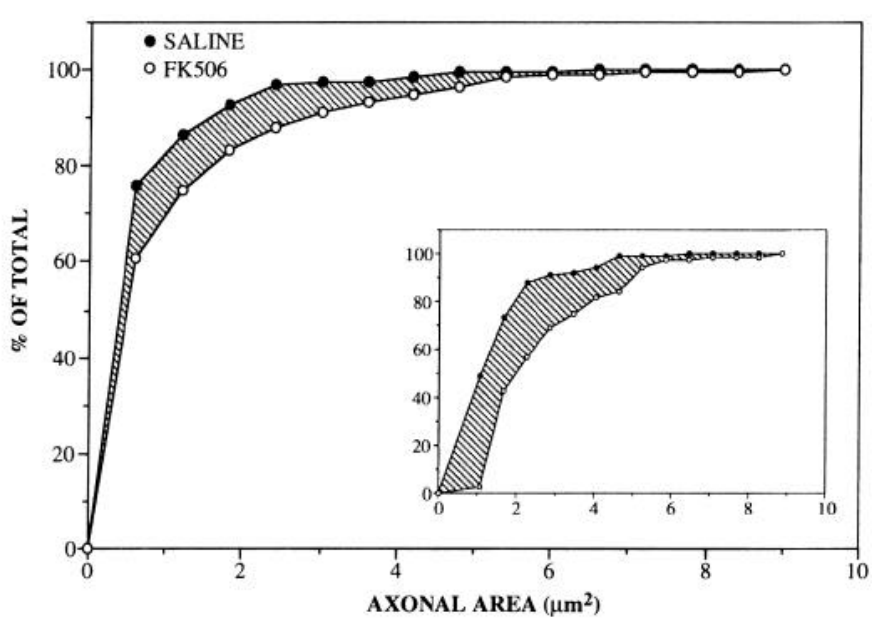

Figure 3. Axons in the soleus nerve are larger in size from FK506treated animals. Cumulative histograms (five animals per group) showing the distributions of axonal areas from FK506-treated and salinetreated animals; each histogram was constructed from 728 and 809 axons, respectively. Inset, Distributions of the top $30 \%$ of axonal areas (presented as a percentage of the total numbers of axons in this subpopulation); each histogram was constructed from 216 and 240 axons, respectively. In both histograms, axonal areas are shifted to larger sizes

axons was analyzed in this group (see Fig. 3 caption). Thus, a possible explanation for the difference in distribution between the two groups is the presence of more small axonal sprouts in the control (saline-treated) group. We therefore rank ordered the axonal areas based upon their size and compared the distributions for the largest $30 \%$ of axons from each group. The distri- butions for the largest $30 \%$ of axons demonstrated a proportionately similar shift to larger sized axons (compared to the entire axonal population) in the FK506-treated rats (Fig. 3, inset). Mean values for axonal area for the top $30 \%$ of axons were significantly $(p<0.005)$ increased (by 93\%) from $1.4 \pm 0.21$ $\mu \mathrm{m}^{2}$ to $2.7 \pm 0.24 \mu \mathrm{m}^{2}$ in saline-treated and FK506-treated animals, respectively.

Intramuscular nerve branches in the interosseus muscles were selected for examination by electron microscopy. This region of the nerve was chosen since we anticipated that the two groups (i.e., FK506 and saline) would demonstrate the most pronounced difference in morphology in this most distal portion of the nerve; this assumption was based upon our previous behavioral studies (Gold et al., 1994a) which showed that at this time-point (i.e., $18 \mathrm{~d})$ the development of functional recovery in the toes was just commencing in the saline-treated animals, whereas the FK506-treated animals demonstrated clinical signs of recovery in the toes $2 \mathrm{~d}$ earlier (Gold et al., 1994a). Intramuscular nerve twigs from the saline-treated animals contained many empty bands of Büngner or few axonal sprouts (Fig. 4A); in a rare instance, two cilia were observed in a Schwann cell (Fig. $4 A$, inset). In contrast, numerous axonal sprouts (Fig. 4B), including a remyelinated axon (Fig. $4 B$, inset), were found in nerve twigs from the FK506-treated animals.

Since measurement of axonal regeneration rate was determined in sensory nerves (see below), we also examined (by electron microscopy on skip-serial sections) muscle spindles in the interosseus muscles (3-5 spindles per muscle; $2-3$ muscles per rat) for evidence of axonal reinnervation. Many (ca. 25\%) muscle spindles examined from the FK506-treated animals con-
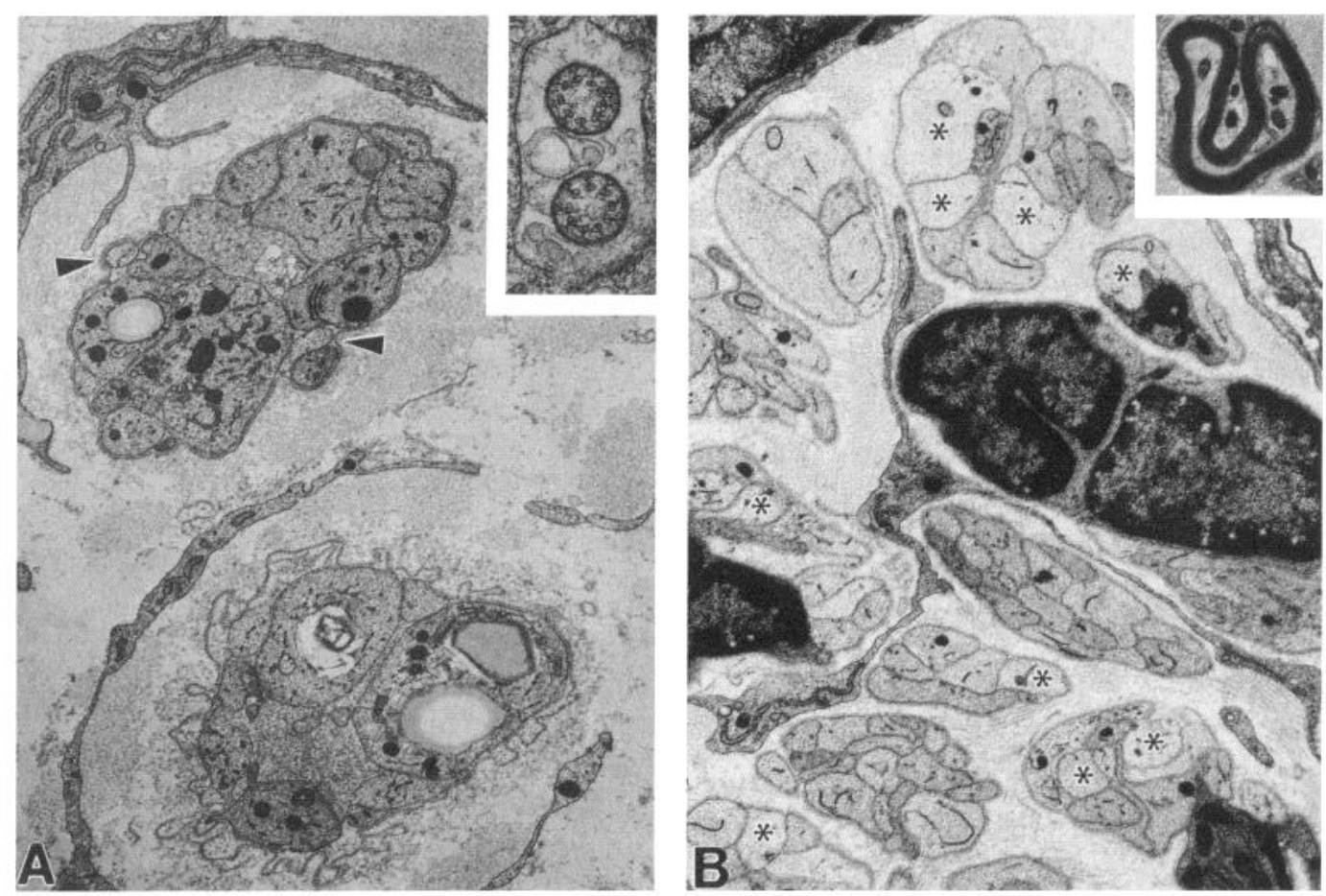

Figure 4. Axonal sprouts have advanced further into the intramuscular nerve branches of interosseus muscles following FK506 administration for $18 \mathrm{~d}$ postaxotomy. A, Representative electron micrograph from a saline-treated animal showing bands of Büngner containing only an occasional axonal sprout (arrowheads). Inset, Two cilia in a Schwann cell from another animal. Note typical neuronal (nonmotile) $9+0$ arrangement of microtubules. B, Representative electron micrograph from an FK506-treated animal showing many large axonal sprouts (asterisks) within Büngner bands. Inset, A small remyelinated axon from another animal. Section is in the paranode as indicated by the marked knuckling of the fiber and the presence of several mitochondria in the Schwann cell cytoplasm (arrow). 7500×; 27,000× (inset in A); $7500 \times($ inset in B). 

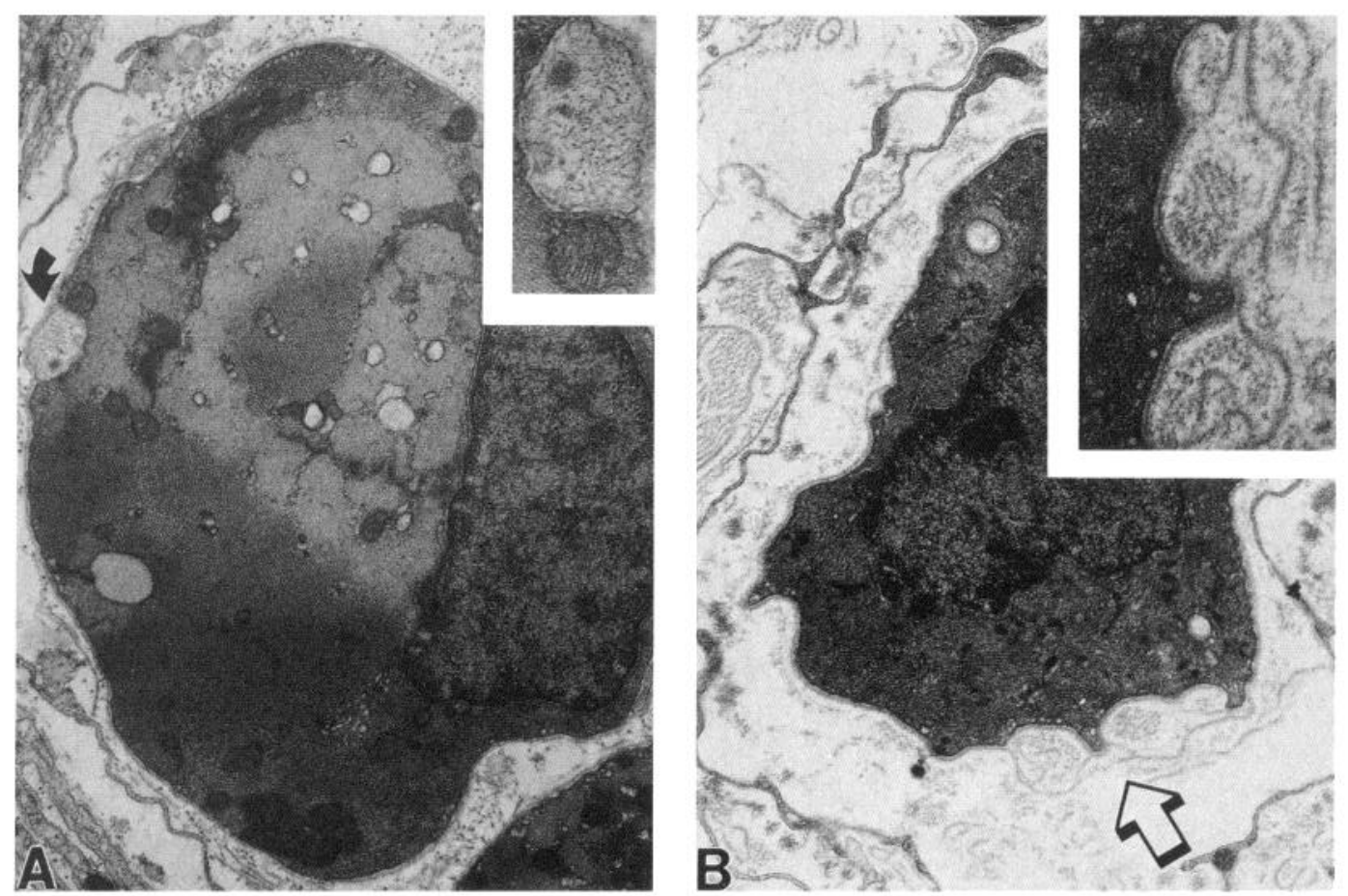

Figure 5. Sensory axons have reinnervated some intrafusal fibers in muscle spindles following FK506 administration for $18 \mathrm{~d}$ postaxotomy. Representative electron micrographs from interosseus muscles. A, Axon (curved arrow) surrounding intrafusal muscle fiber from an FK506-treated animal shown at higher power in inset. $B$, Intrafusal muscle fiber lacking axonal innervation from a saline-treated animal. Note pockets of empty basal lamina associated with indented portion of muscle fiber (open arrow) shown at higher power in inset. 10,000×;20,000× (inset in A); $27,000 \times$ (inset in B).

tained at least one intrafusal fiber surrounded by an axon (Fig. $5 A)$. In contrast, in no instance were axons found to reinnervate intrafusal muscle fibers of saline-treated animals (Fig. $5 B$ ).

\section{FK506 Increases the rate of maximal axonal advance in regenerating sensory nerves}

Nerve outgrowth was determined by measuring the distance traveled by fast axonally transported radiolabeled proteins in

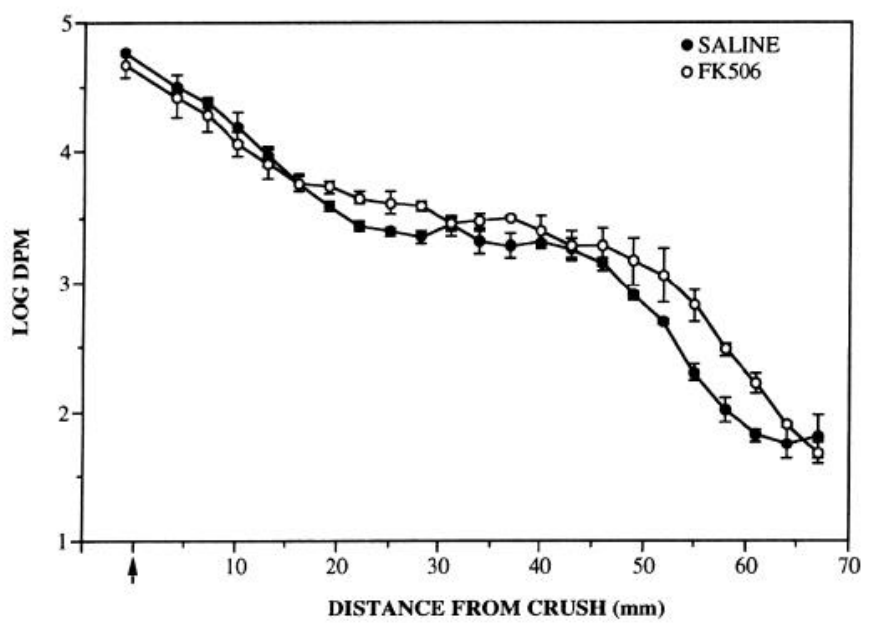

Figure 6. FK506 increases axonal outgrowth distance at $15 \mathrm{~d}$ following nerve crush. Plots showing the average distribution (three animals per group) of radiolabeled proteins $24 \mathrm{hr}$ after radiolabeling the L5 DRG. The front of each transport profile indicates the maximal extent of the growing axonal sprouts which is further advanced along the nerves from the FK506-treated animals. Arrow indicates crush site. Bars are SEM. sensory axons at 10 and $15 \mathrm{~d}$ following axotomy (see Materials and Methods). Radiolabeled profiles showed that the maximal extent of outgrowth was further advanced along the sciatic nerve in FK506-treated compared to saline-treated rats at $10 \mathrm{~d}$ (not shown) and $15 \mathrm{~d}$ (Fig. 6). Regression analysis based upon these two time points (see Material and Methods) demonstrated that the rate of axonal regeneration was significantly $(p<0.05)$ increased (by $16 \%$ ) from $3.8 \mathrm{~mm} / \mathrm{d}$ in saline-treated rats to 4.4 $\mathrm{mm} / \mathrm{d}$ in FK506-treated animals (Fig. 7).

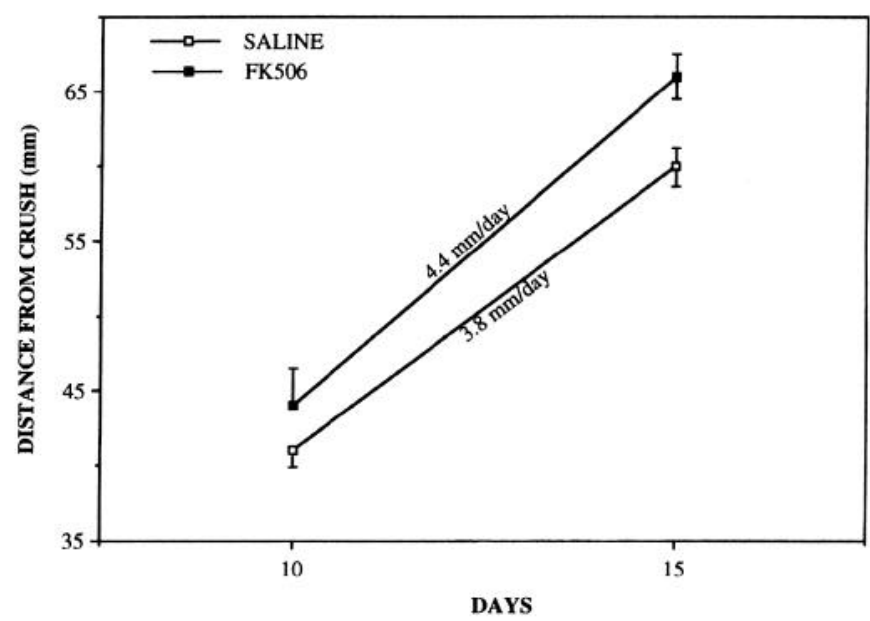

Figure 7. FK506 increases the rate of axonal regeneration. Plots showing mean transport distances measured at 10 (four animals per group) and 15 (three animals per group) $\mathrm{d}$ following nerve crush. By regression analysis, regeneration rate (slope of the line) between these two time points is significantly $(p<0.05)$ increased in the FK506-treated animals by $16 \%$. Bars are SEM. 


\section{Discussion}

The major finding of the present study is that the immunosuppressant FK506 increases the rate of axonal elongation in the rat sciatic nerve, the morphological correlate of this alteration being an increased caliber of regenerating axons. Using radiolabeling procedures to most accurately measure axonal outgrowth distances, we demonstrate that daily subcutaneous injections of a $1 \mathrm{mg} / \mathrm{kg}$ dose of FK506 increases the rate of regeneration for sensory fibers by $16 \%$; it is important to note that our mean value for the rate of axonal regeneration in normal (untreated) rat sciatic nerve is consistent with those previously reported (see, for example, Jacob and McQuarrie, 1991, 1993). While the magnitude of the effect is small, albeit significant, its advantage over other agents reported to enhance nerve regeneration is twofold. First, the present study shows that systemic injections of FK506 enhance the rate of axonal regeneration. To our knowledge, this is the first agent in which systemic exposures have been demonstrated to increase regeneration rate. Sevcral other agents (e.g., insulin growth factor II) have been shown to increase axonal regeneration following continuous infusion directly to the nerve injury site (Glazner et al., 1993) only. Although systemic administrations of the ACTH analog Org 2766 increase functional recovery from a nerve crush injury (De Koning and Gispen, 1987; Sporel-Özakat et al., 1990), rate determinations have not been reported. Second, FK506 is not structurally related to any known growth-promoting factor and it is therefore likely to accelerate regeneration via a novel mechanism (see below). Knowledge of its mechanism of action may shed new light on how regeneration is achieved in neurons. Before discussing how FK506 may speed regeneration, it is important to recognize the limitations of our findings.

\section{Technical considerations}

An important limitation of the present study is that the dose dependency for the effect of FK506 on regeneration rate was not examined. As already stated (see Materials and Methods), only a single dose of FK506 ( $1 \mathrm{mg} / \mathrm{kg})$ was studied due to the limited availability of the drug. Thus, it is possible that FK506 may have a greater effect on regeneration rate than that reported in our study. Moreover, in addition to the need for further studies to determine the optimal dose of FK506 for promoting axonal regeneration, it would be important to examine the ability of newly synthesized FK506 analogs (Holt et al., 1993; Batchelor et al., 1994; Luengo et al., 1994) to alter axonal regeneration.

Morphologically, the nerves from the FK506-treated animals contained larger axons. This could be due to a greater number of small (unmyelinated) axons in the saline group leading to the presence of more axons in these nerves (see Materials and Methods). However, analysis of the top $30 \%$ of axons revealed that the shift in the distribution of axonal areas from the entire population resulted from the presence of a larger caliber axons in the FK506 group. Thus, it is unlikely that FK506 merely reduces the number of small-caliber axons in regenerating nerves. Instead, we believe that by accelerating target reinnervation, nerves from FK506-treated animals contained fewer abortive regenerating sprouts at this time. This is to be supported by the greater level of radiolabeled material in nerves from FK506treated animals ruling out the alternative possibility of fewer axons advancing at a faster rate. Thus, the presence of larger sized axonal sprouts in the nerves to the soleus and medial gastrocnemicus nerves most likely represents the morphological correlate of the greater levels of radiolabeled protein in the distal portion of the nerve. While it is possible that FK506 may also promote myelination, thereby contributing to the production of larger axonal calibers (de Waegh et al., 1992; Cole et al., 1994), such an effect would not negate our conclusion that FK506 accelerates axonal elongation.

\section{FK506 and axonal regeneration}

How might FK506 elicit its effect on axonal elongation? It is well established from studies of T-cells that FK506 activity is mediated by a family of proteins termed FK506-binding-proteins (FKBP); the $12 \mathrm{kDa}$ receptor, FKBP-12 (Harding et al., 1989; Siekierka et al., 1990), is a ubiquitous protein that has been highly conserved throughout evolution (Siekierka et al., 1990) and appears to be the FKBP most likely involved in $5 K 506$ activity (Liu et al., 1991; see Sigal and Dumont, 1992). In the nervous system, Snyder and coworkers (Steiner et al., 1992; Lyons et al., 1995) have recently found that FKBP is also present in neuronal tissue (Steiner et al., 1992) and that mRNA levels for the FKBP increase in peripheral (facial) neurons following axotomy (Lyons et al., 1995). Moreover, brain regions containing high levels of FKBP correspond with high levels of calcineurin (Steiner et al., 1992), a calcium-dependent phosphoserine/phosphothreonine protein phosphatase (also known as PP-2B) which is the FK506-FKBP target in T-cells (Siekierka et al., 1990; Dumont et al., 1992; for review, see Walsh et al., 1992) and in brain (Mukai et al., 1993).

One of the major protein targets for calcineurin in neurons is GAP-43 (see (Skene, 1990) which plays an important role in axonal elongation (Skene and Willard, 1981a,b; for review. see Skene, 1989). GAP-43, a major phosphoprotein in growth cones (Meiri et al., 1986; Skene et al., 1986) and a calcineurin substrate (see Skene, 1990), may provide the biochemical link between the phosphatase activity of calcineurin and motility of the growth cone. Thus, one attractive possibility is that FK506 accelerates axonal regeneration by a direct effect at the level of the growing axonal sprouts; that is, inhibition of calcineurin leading to the subsequent increase in the phosphorylation state (and consequently the activity) of GAP-43. This hypothesis appcars to bc supported by the recent finding that FK506 increases the phosphorylation of GAP-43 in vitro (Steiner et al., 1991). In addition, two preliminary reports (Steiner et al., 1993; Gold et al., 1994b) indicate that FK506 also increases, in a concentration-dependent fashion, stimulus-evoked secretion (a GAP43/B5()-dependent process) in a variety of cell types. In light of the evolutionary linkage between vesicular release of neurotransmitter and membrane addition (Steinhrdt et al., 1994), FK506 may alter neuronal functions via a generalized ability of activated (i.e., phosphorylated) GAP-43 to promote membrane fusion (see Benowitz and Routtenbert, 1987; Skene, 1989; Campagne et al., 1992).

The possibility that inhibition of calcineurin activity accelerates axonal regeneration is apparently supported by the recent in vitro demonstration that agents which inhibit protein kinase C impair regeneration of frog sensory neurons (Ekström et al., 1992). Taken together, these complementary findings suggest that opposing actions of kinases and phosphatases regulate axonal elongation.

Several additional mechanisms by which FK506 may increase axonal regeneration can be proposed. FK.506 could increase growth cone motility by altering $\mathrm{Ca}^{2+}$ levels (Kater and Mills, 1991) via an inhibition of calcineurin-dependent dephosphory- 
lation of $\mathrm{Ca}^{2}$ channels (Armstrong, 1989; Timerman ct al., 1993). In addition, the drug may have an indirect effect on axonal regeneration by increasing the sensitivity of sensory neurons to NGF (Lyons et al., 1994). In this context, it appears that transforming growth factor- $\beta$ (TGF- $\beta$ ), which stimulates NGF synthesis by glial cells (Lindholm et al., 1990), is a natural ligand for FKBP (Wang et al., 1994). Since NGF has been suggested to play a role in axonal elongation (Taniuchi et al., 1988), FK506 could increase regeneration indirectly via an increase in NGF efficacy (Lyons et al., 1994). However, recent evidence does not support a physiological role for NGF in nerve regeneration (Diamond et al., 1992) and, in fact, NGF appears to reduce the extent of axonal regeneration upon intrathecal infusion (B. G. Gold, unpublished observation). An alternative possibility involving the TGF- $\beta$ pathway by which FK506 may indirectly enhance axonal regeneration is suggested by the recent finding (Gucnard et al., 1995) that TGF- $\beta$ increases expression of neuronal-cell adhesion molecules (i.e., N-CAM and LI) on the surface of Schwann cells known to promote neuritic outgrowth in culture (Bixby et al., 1988; Seilheimer and Schachner, 1988). Clearly, additional studies are necessary to provide insight into the underlying mechanism(s) by which FK506 acts to speed axonal elongation.

In summary, we have shown that FK506 increases the rate of axonal regeneration for sensory neurons. Together with our previous behavioral data showing accelerated recovery of motor function (Gold et al., 1994a), it seems likely that FK506 enhances axonal regeneration rate in motor as well as in sensory fibers. We are currently conducting studies to measure the magnitude of the rate change for axonal regeneration in motor neurons. The possibility that inhibitors of the phosphatase calcineurin can be employed to enhance functional recovery from peripheral nerve injury should be explored.

\section{References}

Alessiani M, Cillo U, Fung JJ, Irish W, Alu-Elmagd K, Jain S, Takaya S, Van Thiel D, Starzl TE (1993) Adverse effects of FK506 overdosage after liver transplantation. Transplant Proc 25:628-634.

Armstrong DL (1989) Calcium channel regulation by calcineurin, a $\mathrm{Ca}^{2+}$-activated phosphatase in mammalian brain. Trends Neurosci 12: $117-122$.

Batchelor MJ, Gillespie RJ, Golec JMC, Hedgecock CJR, Jones SD, Murdoch R (1994) Total syntheses of close analogues of the immunosuppressant FK506. Tetrahedron 50:809-825.

Benowitz LI, Routtenbert A (1987) A membrane phosphoprotein associated with neural development, axonal regeneration, phospholipid metabolism, and synaptic plasticity. Trends Neurosci 10:527-531.

Bixby JL, Lilien J, Reichardt LF (1988) Identification of the major proteins that promote neuronal process outgrowth on Schwann cells in vitro. J Cell Biol 107:353-361.

Burkhalter EL, Starzl TE, Van Thiel DH (1994) Severe neurological complications following orthotopic liver transplantation in patients receiving FK 506 and prednisone. J Hepatology 21:572-577.

Campagne MV, Oestreicher AB, DeGraan PNE, Gispen WH (1992) Role of B-50/Gap-43 in nerve growth cone function. In: The nerve growth cone (Letourneau, PC, Kater, SB, Macgano, ER, eds), pp 97109. New York: Raven.

Carroll PB, Rilo HLR, Elmagd KA, Johnson N, Carter C, Wright $\mathrm{H}$, Jegasothy B, Starzl TE, Van Thiel DH (1994) Effect of tacrolimus (FK506) in dystrophic epidermolysis bullosa: rationale and preliminary results. Arch Dermatol 130:1457-1458.

Cole JS, Messing A, Trojanowski JQ, Lee VM-Y (1994) Modulation of axon diameter and neurofilaments by hypomyelinating Schwann Cells in transgenic mice. J Neurosci 14:6956-6966.

De Koning P. Gispen WH (1987) Org. 2766 improves functional and electrophysiological aspects of regenerating sciatic nerve in the rat. Peptides 8:415-422.

De Waegh SM, Lee VM-Y, Brady ST Local modulation of neurofila- ment phosphorylation, axonal caliber, and slow axonal transport by myelinating Schwann cells. Cell 68:451-463.

Diamond J, Foerster A, Holmes M, Coughlin M (1992) Sensory nerves in adult rats regenerate and restore sensory function to the skin independently of endogenous NGF. J Neurosci 12:1467-1476.

Droz B, Warshawsky H (1963) Reliability of the radioautographic technique for the detection of newly synthesized protein. $J$ Histochem Cytochem 11:426-435.

Dumont FJ, Staruch MJ, Koprak SL, Siekierka JJ, Lin CS, Harrison R, Sewell T, Kindt VM, Beattie TR. Wyvratt M. Sigal NH (1992) The immunosuppressive and toxic effects of FK-506 are mechanistically related: pharmacology of a novel antagonist of FK-506 and rapamycin. J Exp Med 176:751-760.

Eidelman BH, Abu-Elmagd K, Wilson J, Fung JJ, Alessiani M, Jain A, Takaya S, Todo SN, Tzakis A, Van Thiel D, Shannon W, Starzl TE (1991) Neurological complications of FK506. Transplant Proc 23: 3175-3178.

Ekströn PAR, Bergstrand H, Ekström A (1992) Effects of kinase inhibitors on regeneration in vitro of adult frog sciatic sensory axons. J Neurosci Res 31:462-469.

Francavilla A, Barone M. Todo S, Zeng Q, Porter KA, Starzl 'T'E (1989) Augmentation of rat liver regeneration by FK506 compared with cyclosporine. Lancet 1:1248-1249.

Glazner GW, Lupien S, Miller JA, Ishii DN (199.3) Insulin-like growth factor II increases the rate of sciatic nerve regeneration in rats. Neuroscience 54:791-797.

Gold BG, Storm-Dickerson T, Austin DR (1994a) The immunosuppressant FK506 increases functional recovery and nerve regeneration following peripheral nerve injury. Restor Neurol Neurosci 6:287296.

Gold BG, Storm-Dickerson T, Katoh K, Allen RG, Austin DR (1994b) FK506 accelerates the rate of axonal regeneration in the rat sciatic nerve and increases secretion of $\beta$-endorphin from AtT-20 cells. Inaugural meeting of the Peripheral Nerve Society, Saint Paul, Minnesota, June 12-16, 1994, p 170.

Guenard V, Gwynn LA, Wood PM (1995) Transforming growth factor- $\beta$ blocks myelination but not ensheathment of axons by Schwann cells in vitro. J Neurosci 15:419-428.

Harding MW, Galat A, Uehling DE, Schreiber SL (1989) A receptor for the immunosuppressant FK506 is a cis-trans peptidyl-prolyl isomerase. Nature 341:758-760

Heitman J, Koller A, Kunz J, Henriquez R, Schmidt A, Movva NR, Hall MN (1993) The immunosuppressant FK506 inhibits amino acid import in Saccharomvces cerevisiae. Mol Cell Biol 13:5010-5019.

Hoffman AL, Makowka L, Banner B, Cai X, Cramer DV, Pascualone A, Todo S, Starzl TE (1990) The use of FK-506 for small intestine allotransplantation. Inhibition of acute rejection and prevention of fatal graft-versus-host disease. Transplant 49:483-490.

Holt DA, Luengo JI, Yamashita DS, Oh H-J, Konialian AL, Yen H-K, Rozamus LW, Brandt M, Bossard MJ, Levy MA, Eggleston DS, Liang J, Schultz LW, Stout TJ, Clardy J (1993) Design, synthesis, and kinetic evaluation of high-affinity FKBP ligands and the $\mathrm{x}$-ray crystal structures of their complexes with FKBP12. J Am Chem Soc 115: 9925-9938.

Jacob JM, McQuarrie IG (1991) Axotomy accelerates slow component b of axonal transport. J Neurobiol 22:570-582.

Jacob JM, McQuarrie IG (1993) Acceleration of axonal outgrowth in rat sciatic nerve at one week after axotomy. J Neurobiol 24:356-367.

Kater SB, Mills LR (1991) Regulation of growth cone behavior by calcium. J Neurosci 1 1:891-899.

Katoh K, Gold BG (1995) FK506 increases axonal regeneration rate in the rat peripheral nervous system. Fourth IBRO World Congress of Neuroscience, Kyoto, Japan, July 9-14, 1995, in press.

Kino T, Hatanaka H, Hashimoto M, Nishiyama H (1987a) FK-506, a novel immunosuppressant isolated from a streptomyces. I. Fermentation, isolation, and physio-chemical and biological characteristics. $\mathrm{J}$ Antibiot 40:1249-1255.

Kino T, Hatanaka $\mathrm{H}$, Miyata S, Inamura $N$, Nishiyama M, Yajima T, Goto T, Okuhara M, Kohsaka M, Aoki H, Ochiai T (1987b) FK506, a novel immunosuppressant isolated from a streptomyces. II. Immunosuppressive effect of FK-506 in vitro. J Antibiot 40:12561265.

Klintmalm GB (1994) A comparison of tacrolimus (FK.506) and cyclosporine for immunosuppression in liver transplantation. $\mathrm{N}$ Engl $\mathrm{J}$ Med 1110-1115. 
Lindholm D, Hengerer B, Zafra F, Thoenen H (1990) Transforming growth factor- $\beta 1$ stimulates expression of nerve growth factor in the rat CNS. Neuroreport 1:9-12.

Liu J, Farmer ID, Lane WS, Friedman J, Weissman I, Schreiber SI, (1991) Calcineurin is a common target of cyclophilin-cyclosporin A and FKBP-FK506 complexes. Cell 66:807-815.

Lucngo JI, Konialian-Bcck A, Levy MA, Brandt M, Eggleston DS, Ilolt DA (1994) Synthesis and structure-activity relationships of macrocyclic FKBP ligands. Bioorg Med Chem Lett 4:321-324

Lyons WE, George EB, Dawson IM, Steiner JP, Snyder SH (1994) Immunosuppressant FK506 promotes neurite outgrowth in cultures of PC12 cells and sensory ganglia. Proc Natl Acad Sci USA 91: 3191-3195.

Lyons WE, Steiner JP, Snyder SH Dawson TM (1995) Neuronal regeneration enhances the expression of the immunophilin FKBP-12. J Neurosci 15:2985-2994.

Meiri FK, Pfenninger KH, Willard MD (1986) Growth-associated protein, GAP-43, a polypeptide that is induced when neurons extend axons, is a component of growth cones and corresponds to pp46, a major polypeptide of a subcellular fraction enriched in growth cones. Proc Natl Acad Sci USA 83:3537-3541.

Mukai H, Kuno T, Chang C-D, Lane B, Luly JR, Tanaka C (1993) FKBP12-FK 506 complex inhihits phosphatase activity of two mammalian isoforms of calcineurin irrespective of their substrates or activation mechanisms. J Biochem 113:292-298.

Ochs S, Ranish N (1970) Metabolic dependence of fast axoplasmic transport in nerve. Science 167:878-879.

Schmidt A. Hall MN, Koller A (1994) Two FK506 resistance-conferring genes in Saccharoymces cerevisiae, TATI and TAT2, encode amino acid permeases mediating tyrosine and tryptophan uptake. Mol Cell Biol 14:6597-6606.

Seilheimer B, Schachner M (1988) Studies of adhesion molecules mediating interactions between cells of peripheral nervous system indicate a major role for $\mathrm{Ll}$ in mediating sensory neuron growth on Schwann cells in culture. J Cell Biol 107:341-351

Siekierka JJ, Wiederrecht G, Greulich H, Boulton D, Hung SHY, Cryan J, Hodges PJ, Sigal NH (1990) The cytosolic-binding protein for the immunosuppressant FK-506 is both a ubiquitous and highly conserved peptidyl-prolyl cis-trans isomerase. J Biol Chem 265:2101121015.

Sigal NH, Dumont FJ (1992) Cyclosporin A, FK-506, and rapamycin: pharmacologic probes of lymphocyte signal transduction. Annu Rev Immunol 10:519-560.

Skene JHP (1989) Axonal growth-associated proteins. Annu Rev Neurosci $12: 127-156$.

Skene JHP (1990) GAP-43 as a 'calmodulin sponge' and some impli- cations for calcium signaling in axon terminals. Neurosci Res 13 S112-S125.

Skene JHP, Willard MB (1981a) Axonally transported proteins associated with growth in rabbit central and peripheral nervous system. J Cell Biol 89:96-103.

Skene JHP, Willard MB (1981b) Changes in axonally transported proteins during axon regeneration in toad retinal ganglion cells. J Cell Biol 89:86-95.

Skene JHP, Jacobson RD, Snipes GJ, McGuire CB, Norden JJ, Freeman JA (1986) A protein induced during nerve growth (G^P-43) is a major component of growth-cone membranes. Science 233:783-786.

Sporel-Özakat RE, Edwards PM, Gerritsen van der Hoop G, Gispen WH (1990) An ACTH(4-9) analog, Org 2766, improves recovery from acrylamide neuropathy in rats. Eur J Pharmacol 186:181-187.

Starzl TE, Makowka L, Todo S (1987) FK-506: A potential breakthrough in immunosuppression. Transplant Proc 19:S3-S104.

Starzl TE, Todo S, Fung J, Demetris AJ, Venkataramman R, Jain A (1989) FK-506 for liver, kidney, and pancreas transplantation. Lancet 2:1000-1004.

Steiner JP, Dawson TM, Fotuhi C, Glatt C, Snowman AM, Cohen N, Snyder SH (1991) The immunosuppressant FK-506 enhances phosphorylation of GAP43: implications for a role in modulation of growth cone function and neurotransmitter release. Soc Neurosci Abstr 18:603.

Steiner JP, Dawson TM, Fotuhi M, Glatt CE, Snowman AMM, Cohen N, Snyder SH (1992) High brain densities of the immunophilin FKBP colocalized with calcineurin. Nature 358:584-587.

Steiner JP, Dawson TM, Snyder SH (1993) Immunophilin regulation of neurotransmitter release. Soc Neurosci Abstr 19:932.

Steinhrdt RA, Bi G, Alderton JM (1994) Cell membrane resealing by a vesicular mechanism similar to neurotransmitter release. Science 263:390-393.

Taniuchi M, Clark HR, Schweitzer JB, Johnson EM Jr (1988) Expression of nerve growth factor receptors by Schwann cells of axotomized peripheral nerves: ultrastructural location, suppression by axonal contact, and binding properties. J Neurosci 8:664-681.

Timerman AP, Ogunbumni E, Freund E, Wiederrecht G, Marks AR. Fleischer S (1993) The calcium release channel of sarcoplasmic reticulum is modulated by FK-506-binding protein. J Biol Chem 268: 22992-22999.

Walsh CT, Zydowsky LD, McKeon FD (1992) Cyclosporin A, the cyclophilin class of peptidylprolyl isomerases, and blockade of $\mathrm{T}$ cell signal transduction. J Biol Chem 267:13115-13!18.

Wang GT, Lane B, Fesik SW, Petros A, Luly J, Krafft GA (1994) Synthesis and FKBP binding of small molecule mimics of the tricarbonyl region of FK506. Bioorg Med Chem Lett 4:1161-1166.

Yamamoto S, Jiang H, Kato R (1994) Stimulation of hair growth by topical application of FK506, a potent immunosuppressive agent. J Invest Dermatol 102:160-164. 